\title{
DNA of Brugia malayi detected in several mosquito species collected from Balangan District, South Borneo Province, Indonesia
}

\author{
Supriyono Supriyono1(i) and Suriyani $\operatorname{Tan}^{2}$ (D) \\ 1. Division of Parasitology and Medical Entomology, Faculty of Veterinary Medicine, IPB University, Bogor 16680, \\ West Java, Indonesia; 2. Department of Parasitology, Faculty of Medicine, Trisakti University, Jakarta, Indonesia. \\ Corresponding author: Suriyani Tan, e-mail: suriyanitan@gmail.com \\ Co-author: SS: supri.supriyono27@gmail.com \\ Received: 17-01-2020, Accepted: 21-04-2020, Published online: 30-05-2020
}

doi: www.doi.org/10.14202/vetworld.2020.996-1000 How to cite this article: Supriyono S, Tan S (2020) DNA of Brugia malayi detected in several mosquito species collected from Balangan District, South Borneo Province, Indonesia, Veterinary World, 13(5): 996-1000.

\begin{abstract}
Background and Aim: Lymphatic filariasis (LF) is a lesser-known parasitic disease, which contributes to significant decreases in overall health. This study investigated the presence of Brugia malayi in mosquitoes collected in the South Borneo Province, Indonesia.

Materials and Methods: Mosquitoes were collected through bare leg collection methods after sunset in several areas of the Hukai and Gulinggang villages in the Balangan District. The collected mosquitoes were identified based on morphological features and dissected to find microfilaria and then pooled through species for polymerase chain reaction (PCR) microfilaria detection.

Results: A total of 837 female mosquitoes consisting of at least 14 species were selected; they were dissected, and no microfilariae were found. Mosquitoes were divided into 69 pools for PCR analysis. PCR revealed that $8.7 \%$ (6/69) of the pools were positive for B. malayi, including Mansonia annulifera (4 pools), Aedes albopictus (1 pool), and Culex tritaeniorhynchus (1 pool).

Conclusion: These results suggested that mosquito dissection was not an optimum method for finding microfilaria. M. annulifera, C. tritaeniorhynchus, and A. albopictus mosquitoes might play an important role in the transmission of LF in the Balangan District. Information from this study could be used for the prevention of transmission or vector control programs in Indonesia.
\end{abstract}

Keywords: Brugia malayi, lymphatic filariasis, polymerase chain reaction.

\section{Introduction}

Lymphatic filariasis (LF) remains a public health problem and possesses a significant morbidity risk to a large proportion of low-income individuals and families in several countries [1,2]. At present, more than half of the world's inhabitants reside in high-risk areas for this disease. Approximately 50\% of infections are those who live in Southeast Asia, including Indonesia [3]. Once this parasite enters the host, the worms lodge in the lymphatic vessels of the host and causes swelling of the arms, legs, and genital organs, leading to debilitating impacts and suffering to the patient [4]. In 2000, the WHO strived to eliminate LF by announcing the Global Program to Eliminate LF and has targeted LF for elimination as a public health problem by the year 2020. Accordingly, the Indonesian Ministry of Health has applied two strategies. The first strategy is aimed at reducing and eliminating transmission by mass drug administration, while the second involves reducing

Copyright: Supriyono and Tan. Open Access. This article is distributed under the terms of the Creative Commons Attribution 4.0 International License (http://creativecommons.org/licenses/ by/4.0/), which permits unrestricted use, distribution, and reproduction in any medium, provided you give appropriate credit to the original author(s) and the source, provide a link to the Creative Commons license, and indicate if changes were made. The Creative Commons Public Domain Dedication waiver (http:// creativecommons.org/publicdomain/zero/1.0/) applies to the data made available in this article, unless otherwise stated. and preventing morbidity in the affected persons [5]. These strategies gained little success; however, epidemiology data showed that in 2016, as many as 29 provinces were still considered endemic areas, with the highest prevalence rates in East Indonesia [6,7].

$\mathrm{LF}$ is a vector-borne disease caused by three species of tissue nematodes, Wuchereria bancrofti, Brugia malayi, and Brugia timori, all of which are endemic to several areas of Indonesia. This condition has complicated the elimination program in Indonesia, as it is the only country with all three species. The following are other challenges for LF elimination programs: (1) Indonesia is comprised of multiple Islands making the distribution of drugs uneven [8], and (2) the geography of Indonesia includes forest and paddy fields, which are suitable mosquito breeding grounds. Of the three main species, $B$. malay $i$ alone accounted for $70 \%$ of the LF infection in Indonesia [9]. There are 23 species of mosquitoes, which have already been identified as vectors of LF from four genera (Culex, Anopheles, Mansonia, and Aedes). The zoophilic type of B. malayi is commonly found in Southeast Asia, including Indonesia; it involves animals as the reservoir host and is transmitted by Mansonia mosquitoes, while the anthropophilic type is transmitted by Anopheles [10]. Since the WHO supplemental strategy is to use the approach of vector control, we should 
fully understand the behavior of these mosquitoes. The Balangan District in South Kalimantan is one of the endemic areas of filariasis with forest, mountains, and swampy areas. The population was 112,430 inhabitants with the majority farmers of rubber plantations [11]. In 2014, the Balangan District Department of Health reported an outbreak of filariasis in several villages, such as Hukai and Gulinggang. The LF patients were generally diagnosed by Giemsa-stained blood smear examination. In $2015,19 \%(4 / 21)$ of patients in the Balangan District were then reported positive with filariasis by polymerase chain reaction (PCR) [12].

The confirmation of vector capacity in microfilaria transmission is important for understanding the status of the disease. Until recently, the only way to measure the infectivity of mosquitoes was through the dissection method. However, dissection is not practical for detecting infection in mosquitoes, particularly when infectivity is low. PCR is a molecular approach that has the capacity for monitoring filariasis and may help to avoid premature cessation of the control programs. This study investigated the presence of B. malayi in mosquitoes collected in the South Borneo Province, Indonesia.

This study aimed to determine the potential vector of $B$. malayi through PCR to support the prevention and protection of the Balangan District, South Kalimantan, Indonesia, from a resurgence of filariasis.

\section{Materials and Methods}

\section{Ethics approval}

This research and all subjects involved in this research obtained an ethics letter from the Faculty of Trisakti University Medicine.

\section{Collection of mosquitoes}

Adult female mosquitoes were collected by bare leg collection in several areas of the Hukai and Gulinggang villages in the Balangan District, Borneo Province (Figure-1) from January to March 2015. Leg collection involved the following: The catcher sat on a chair either indoors or outdoors with their bare legs exposed and caught landing mosquitoes through aspirator $[13,14]$. The collected mosquitoes were identified based on morphological features [15] and were then dissected to determine the infection rates of microfilaria. If no filaria was detected, the mosquitoes were pooled based on the species for detecting microfilaria through PCR analysis (Table-1).

\section{DNA extraction}

The DNA from the pooled mosquitoes was extracted by a GeneJET Genomic DNA Purification Kit (Thermo Fisher Scientific, USA), according to the manufacturer's instructions. Detection of microfilaria was performed using a specific primer for $B$. malayi (Hha1 F 5'-GCG CAT AAA TTC ATC AGC3', Hhal R 5'-GCG CAA AAC TTA ATT ACA AAA GC-3', AIT biotech) [16]. PCR was conducted in $50 \mu 1$ reaction mixtures with the master mix reagents for the PCR, which consisted of Taq DNA polymerase $(0.05 \mathrm{U} / \mu \mathrm{L})$, reaction buffer $(4 \mathrm{mM} \mathrm{MgCl})$, dNTPs ( $0.4 \mathrm{mM}$ each), and oligonucleotide primers $(0.1 \mu \mathrm{M}$ each). The thermal cycling conditions were 35 cycles at $95^{\circ} \mathrm{C}$ for $3 \mathrm{~min}$ followed by $95^{\circ} \mathrm{C}$ for $30 \mathrm{~min}, 57^{\circ} \mathrm{C}$ for $30 \mathrm{~s}, 72^{\circ} \mathrm{C}$ for $1 \mathrm{~min}$, and a final extension step at $72^{\circ} \mathrm{C}$ for $1 \mathrm{~min}$. PCR products were separated by electrophoresis on a $2 \%$ agarose gel, detected by SYBR staining, and visualized with a UVITEC Cambridge

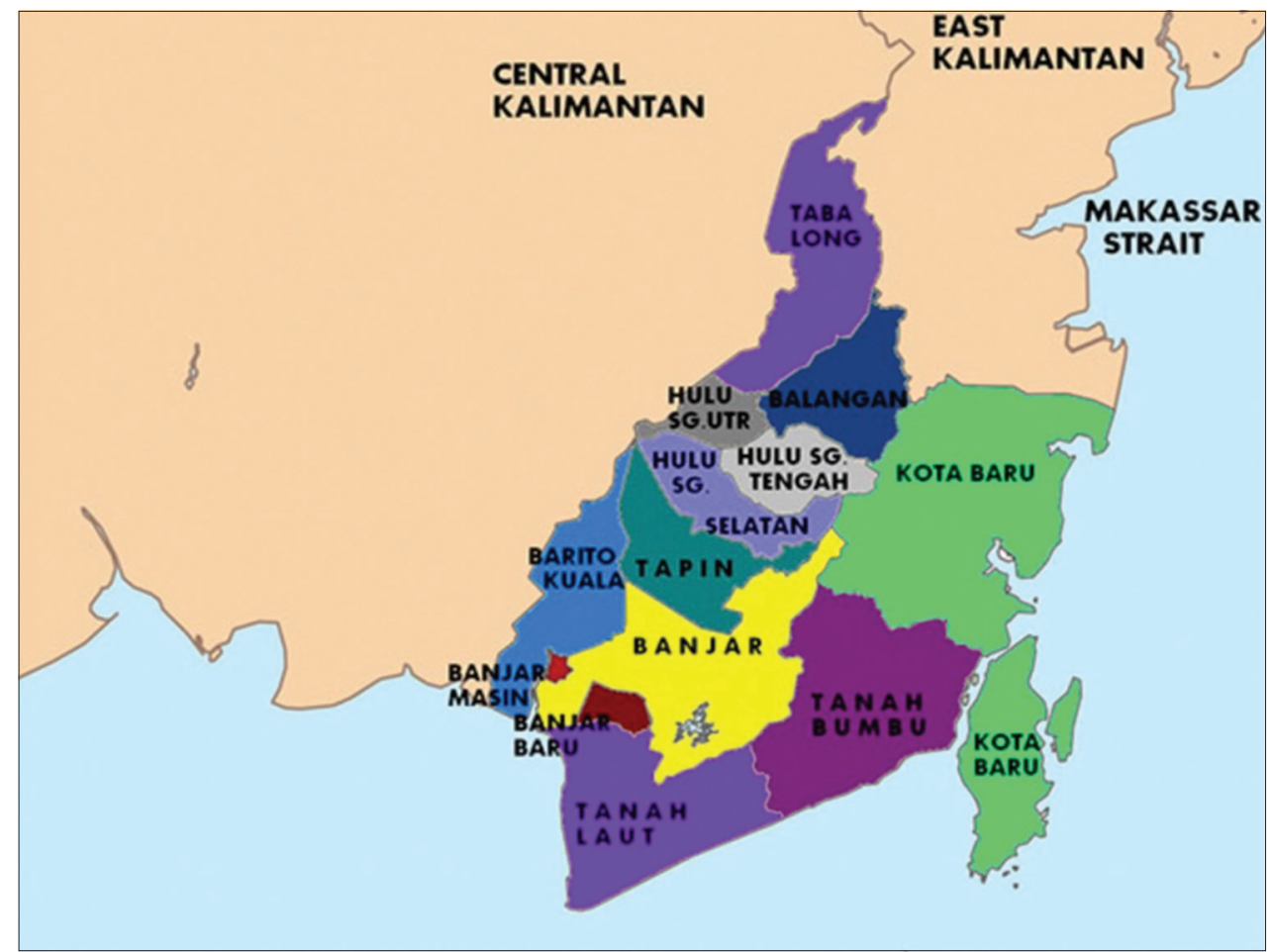

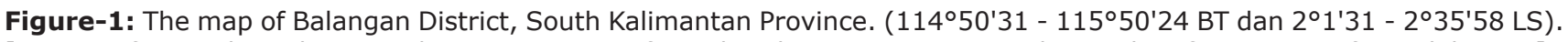
[Source of Latitude and Longitude: Government of South Kalimantan Province. Photo taken from www.infopendaki.com]. 
Gel Documentation system. DNA was determined to be microfilaria positive in our previous study served as positive control.

\section{Results}

In this study, 837 selected female mosquitoes that consisted of at least 14 species were divided into 69 pools ranging between 7 and 43 mosquitoes (Table-1). All selected female mosquitoes were dissected, and no microfilaria was found. The mosquitoes were then subjected to a determination of microfilaria by PCR, and amplification of the $B$. malayi microfilariae DNA using a species-specific primer was demonstrated by the presence of a 322-bp PCR product (Figures-2-5). PCR investigation revealed that $8.7 \%(6 / 69)$ of the pools were positive for $B$. malayi, such as Mansonia annulifera (4 pools), Aedes albopictus (1 pool), and Culex tritaeniorhynchus (1 pool).

Table-1: The collected mosquitoes, no. of pools and positive sample.

\begin{tabular}{lccc}
\hline Mosquito species & $\begin{array}{c}\text { Total } \\
\text { mosquitoes }\end{array}$ & $\begin{array}{c}\text { No. of } \\
\text { pool }\end{array}$ & $\begin{array}{c}\text { No. of } \\
\text { positive pool }\end{array}$ \\
\hline Mansonia annulifera & 425 & 10 & 4 \\
Mansonia annulata & 120 & 29 & 0 \\
Mansonia bonneae & 53 & 7 & 0 \\
Mansonia uniformis & 17 & 2 & 0 \\
Mansonia dives & 8 & 1 & 0 \\
Aedes albopictus & 55 & 5 & 1 \\
Aedes. spp. & 5 & $\mathrm{ND}$ & 0 \\
Anopheles & 12 & 1 & 0 \\
barbirostris & & & \\
Anopheles letifer & 7 & 1 & 0 \\
Armigeres spp. & 36 & 3 & 0 \\
Culex & 50 & 5 & 1 \\
tritaeniorhynchus & & & \\
Culex & 34 & 3 & 0 \\
quinquefasciatus & & & \\
Culex gelidus & 14 & 2 & 0 \\
Aedes aegypti & 1 & $\mathrm{ND}$ & $\mathrm{ND}$ \\
Total & 837 & 69 & $6(8.7 \%)$ \\
\hline
\end{tabular}

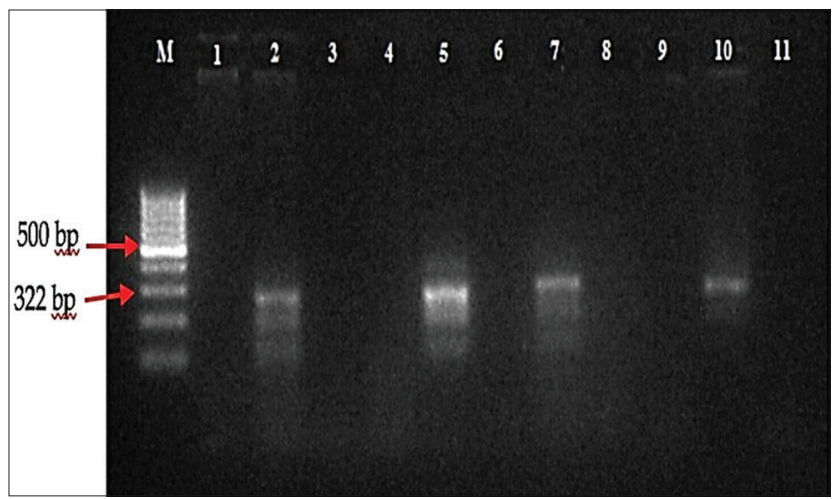

Figure-2: Polymerase chain reaction profile of Brugia malayi from mosquitoes collected in Gulinggang village. M: DNA Marker/ladder 100 bp, column 1-2: Pools of Mansonia annulifera, column 3: Pool of Ma. bonneae, column 4: Pool of Mansonia annulata, column 5: Positive control, column 6-7: Pools of Mansonia annulifera, column 8: Pool of Nyamuk Mansonia bonneae, column 9: Pool of Mansonia annulata, column 10: Positive control and column 11: Negative control.

\section{Discussion}

PCR diagnosis was used for screening of B. malayi in the Balangan District, South Borneo

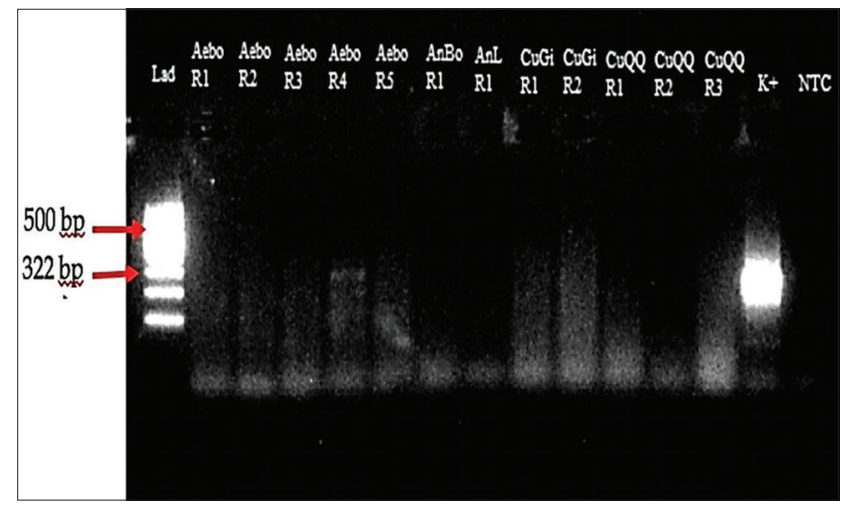

Figure-3: Polymerase chain reaction profile of Brugia malayi from mosquitoes collected in Gulinggang village. Column Lad: DNA Marker, column Aebo R1 - R5: Pool of Aedes albopictus, column AnBo R1: Pool of Anopheles barbirostris, column AnL R1: Pool of Anopheles letifer, column CuGi R1-R2: Pool of Culex gelidus, column CuQQ R1-R3: Pool of Culex quinquefasciatus, column K+: Positive control, and column NTC: Negative control.

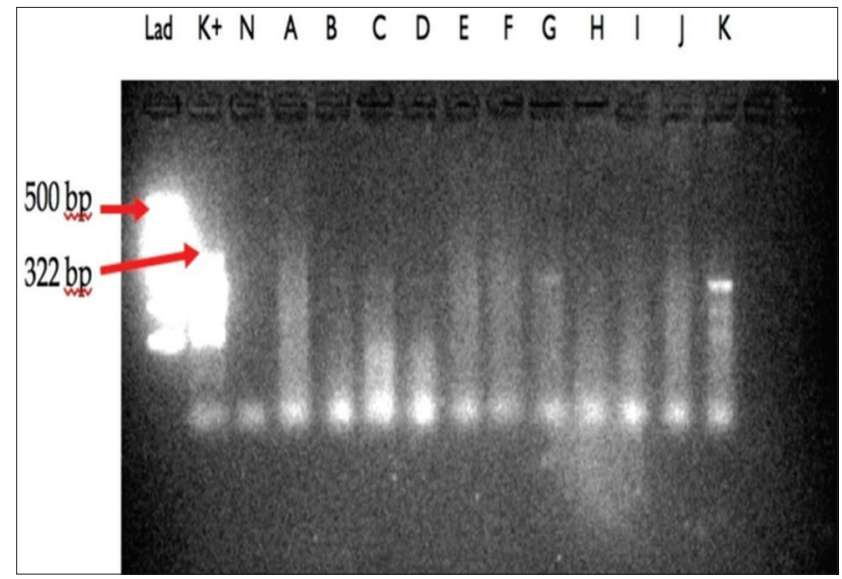

Figure-4: Polymerase chain reaction profile of Brugia malayi from mosquitoes collected in Gulinggang and Hukai villages. Column Lad: DNA Marker, column $\mathrm{K}+$ : Positive control, column N: Negative control, column A: Pool of Aedes albopictus, column B-D: Pool of Armigeres sp. and column E-K: Pool of Mansonia annulifera.

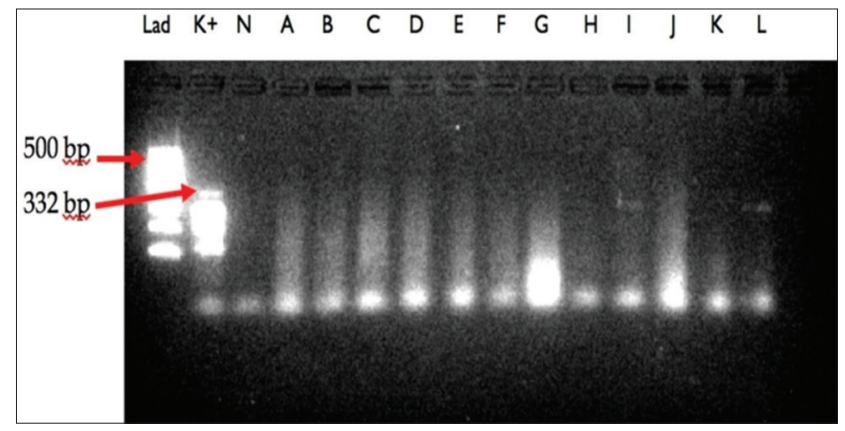

Figure-5: Polymerase chain reaction profile of $B$. malayi from mosquitoes collected in Gulinggang and Hukai villages. column Lad: DNA Marker, column $\mathrm{K}+$ : positive control, column N: negative control, column A-G: pool of Ma. annulata, column $\mathrm{H}-\mathrm{L}$ : pool of $\mathrm{Cx}$. tritaeniorhynchus and column E-K: pool of Mansonia annulifera. 
Province. The selected female mosquitoes that were reported negative of microfilaria infection by microscopy methods were used for molecular analysis. The PCR method was found to be significantly more sensitive compared to microscopy in detecting the filarial parasite in the collected mosquito samples. Our previous study indicated that no mosquitoes were found to be infected with microfilaria when dissected [14]. In this study, four out of ten pools of $M$. annulifera were positive for B. malayi. Several studies have revealed that the genus Mansonia was reportedly the main vector of the zoophilic type of $B$. malayi in several areas in Indonesia, such as the South Sumatra and Jambi Provinces, Sumatra Island [9,17].

Interestingly, in this study, we found a positive sample for both A. albopictus and C. tritaeniorhynchus collected from the Gulinggang village. Since $A$. albopictus and C. tritaeniorhynchus were not previously considered primary vectors of $B$. malayi, this result suggested that these mosquitoes might play an important role in transmitting $B$. malayi in the Balangan District. A study in India showed that the genus Culex was considered to be the main vector of the filarial parasite $W$. bancrofti that causes human LF [18], while the genus Aedes particularly Aedes aegypti was not found to be an efficient vector of $B$. malayi [19]. Since this study used the bare leg method for mosquito collection, we hypothesized that the presence of the specific $322 \mathrm{bp}$ bands found in the pools of A. albopictus and C. tritaeniorhynchus came from mosquitoes that had just fed on the blood of infected subjects. Gulinggang and Hukai villages are close to a big open swamp and irrigated fields and surrounded by rubber plantations. There were many aquatic plants in the swamp; therefore, it was full of potential breeding places for mosquitoes, particularly the genus Mansonia. A previous study revealed that swamps with many aquatic plants are the ideal breeding places for Mansonia spp. [20]. In addition, most of the people in these villages were farmers of rubber plantations. Thus, their activities in the rubber plantation after sunset exposed them more frequently to infected mosquitoes and increased the possibility of contracting B. malayi. Our previous reports also indicated that several cats in Gulinggang village were found to be positive for B. malayi [13] and four out of 21 persons in Balangan District who had received diethylcarbamazine for 10 days exhibited positive DNA for B. malayi by PCR [12]. B. malayi has been known to have multiple definitive hosts, such as humans, monkeys, domestic cats, or forest carnivores. A limitation of this study was that we could not differentiate between the infective and infected mosquitoes, as the head, thorax, and abdomen were not tested separately. However, we successfully detected the presence of DNA for Brugia spp. in M. annulifera, C. tritaeniorhynchus, and A. albopictus by PCR. The existence of multiple mosquito vectors combined with abundant breeding places has allowed the reservoir in these villages to be maintained; therefore, the potential transmission of $B$. malayi might become a future threat to human health.

\section{Conclusion}

While the genus Mansonia remains the main vector in the Balangan District, South Borneo Province, this study showed that additional research is required on another genus of mosquitoes as they might serve as alternative vectors for $B$. malayi. These results should impact future vector control programs in Indonesia, as the control program should not focus only on the main vector, and it should be applied based on the results of future bionomic studies on mosquito vectors.

\section{Authors' Contributions}

SS and ST designed the experimental protocol. ST collected and analyzed the samples. SS and ST drafted and corrected the manuscript. Both authors read and approved the final manuscript.

\section{Acknowledgments}

The authors express the highest gratitude to the various parties who have assisted in the implementation of this research, including heads and inhabitants of Hukai and Gulinggang villages in Balangan District and Laboratory staff in a molecular laboratory in the Faculty of Medicine, Trisakti University. This study was funded by the Trisakti University as research grant holder of the Directorate General of Higher Education, Ministry of Research, Technology and Higher Education, Indonesia under The Outstanding Research in Higher Education scheme with grant No. $350 / \mathrm{K} 3 / \mathrm{KM} / 2015$. The funders had no role in the study design, data collection, and analysis, decision to publish, or preparation of the manuscript.

\section{Competing Interests}

The authors declare that they have no competing interests.

\section{Publisher's Note}

Veterinary World remains neutral with regard to jurisdictional claims in published map and institutional affiliation.

\section{References}

1. Otsuji, Y. (2011) History, epidemiology and control of filariasis. Trop. Med. Health., 39(1): 3-13.

2. Boko-Collins, P.M., Ogouyemi-Hounto, A., AdjinacouBadou, E.G., Gbaguidi-Saizonou, L., Dossa, N.I., Dare, A., Ibikounle, M., Zoerhoff, K.L., Cohn, D.A. and Batcho, W. (2019) Assessment of treatment impact on lymphatic filariasis in 13 districts of Benin: Progress toward elimination in nine districts despite persistence of transmission in some areas. Parasit. Vectors, 12(1): 276.

3. Specht, S., Suma, T.K., Pedrique, B. and Hoerauf, A.A. (2019) Elimination of lymphatic filariasis in South East Asia. BMJ, 364: k5198.

4. Allen, T., Taleo, F., Graves, P.M., Wood, P., Taleo, G., Baker, M., Bradley, M. and Ichimori, K. (2017) Impact of the lymphatic filariasis control program towards elimination 
of filariasis in Vanuatu, 1997-2006. Trop. Med. Health, 45(1): 8

5. Titaley, C.R., Damayanti, R., Soeharno, N., Mu'asyaroh, A., Bradley, M., Lynam, T. and Krentel A. (2018) Assessing knowledge about lymphatic filariasis and the implementation of mass drug administration amongst drug deliverers in three districts/cities of Indonesia. Parasit. Vectors, 11(1): 315 .

6. Wibawa, T. and Satoto, T.B.T. (2016) Magnitude of neglected tropical diseases in Indonesia at postmillennium development goals era. J. Trop Med., 2016 Article ID 5716785.

7. Lee, J. and Ryu, J.S. (2019) Current status of parasite infections in Indonesia: A literature review. Korean J. Parasitol., 57(4): 329-339.

8. Tan, M., Kusriastuti, R., Savioli, L. and Hotez, P.J. (2014) Indonesia: An emerging market economy beset by neglected tropical diseases (NTDs). PLoS Negl. Trop. Dis., 8(2): e2449.

9. Mulyaningsih, B., Umniyati, S.R., Hadisusanto, S. and Edyansyah, E. (2019) Mansonia uniformis: A locally important vector of Brugia malayi nocturnally sub-periodic type in South Sumatera of Indonesia. Southeast Asian J. Trop. Med. Public Health, 50(4): 635-642.

10. McNulty, S.N., Mitreva, M., Weil, G.J. and Fischer, P.U. (2013) Inter and intra-specific diversity of parasites that cause lymphatic filariasis. Infect. Genet. Evol., 14: 137-146.

11. Government of Balangan District. (2020). Available from: https://www.balangankab.go.id/?set=viewprofil\&id=27. Retrieved on 06-04-2020.

12. Tan, S., Supriyono, S. and Ullyartha, H. (2016) Comparison of microscopic to PCR for detecting microfilaria in $21 \mathrm{lym}$ phatic filariasis patients treated with diethylcarbamazine. Indones. J. Biomed. Sci., 10(1): 17-20.
13. Supriyono, Tan, S. and Hadi, U.K. (2017) Behavior of Mansonia and potency of reservoir on transmitting of filariasis in Gulinggang village Balangan District South Kalimantan Province. J. Aspirator, 9(1): 1-10.

14. Supriyono, Tan, S. and Hadi, U.K. (2019) Mosquito diversity and habitat characteristic in Juai Subdistrict, Balangan District, South Kalimantan Province. J. Aspirator, 11(1): 19-28.

15. Rampa, R. (1982) A guide to the genera of mosquitoes (Diptera: Culicidae) of Thailand with illustrated keys, biological notes and preservation and mounting techniques. Mosq. Syst., 14(3): 139-208.

16. Saeed, M., Siddiqui, S., Bajpai, P., Srivastava, A.K. and Mustafa, H. (2014) Amplification of Brugia malayi DNA using Hhal primer as a tool. Open Conf. Proc. J., 5(5): 38-40.

17. Santoso, S., Yahya, Y., Suryaningtyas, N.H. and Rahayu, K.S. (2015) Dissection and PCR-based detection of Brugia malayi on Mansonia spp in Tanjung Jabung Timur District. J. Aspirator, 7(1): 29-35.

18. Shriram, A.N., Krishnamoorthy, K. and Vijayachari, P. (2015) Diurnally subperiodic filariasis among the Nicobarese of Nicobar district epidemiology, vector dynamics and prospects of elimination. Indian J. Med. Res., 141(5): 598-607.

19. Ariani, C.V., Juneja, P., Smith, S., Tinsley, M.C. and Jiggins, F.M. (2015) Vector competence of mosquitoes for filarial nematodes is affected by age and nutrient limitation. Exp. Gerontol., 61(7): 47-53.

20. Sapada, I.E., Anwar, C. and Priadi, D.P. (2015) Environmental and socio-economic factors associated with cases of clinical filariasis in Banyuasin district of South Sumatera, Indonesia. Int. J. Collab. Res. Intern. Med. Public Health, 7(6): 132-140. 